\title{
Review on Streptokinase with its Antigenic Determinants and Perspectives to Develop its Recombinant Enzyme with Minimum Immunogenicity
}

\author{
Ghulam Akbar' ${ }^{*}, M_{\text {uhammad Anjum Zia }}{ }^{1}$, Ali Ahmad ${ }^{2}$, Neha Arooj ${ }^{1}$ and Shahneela Nusrat ${ }^{1}$ \\ ${ }^{1}$ Department of Biochemistry, University of Agriculture, Faisalabad, 38000, Pakistan; ${ }^{2}$ Department of Agronomy, University of \\ Agriculture, Faisalabad, 38000, Pakistan.
}

Abstract | Cardiovascular diseases are the leading cause of death along the world about 30\% of all deaths occur due to cardiovascular diseases. Among fibrinolytic enzymes streptokinase (SK) is commonly used in the world to cure heart diseases because its low cost and efficacy. It's a microbial origin enzyme produced especially by Streptococcus bacterial spp. Therefore, it is antigenic in nature due to microbial source which restricts its use. However, it is necessary to truncate antigenic regions present in the SK gene for the removal of streptokinase antigenicity. The basic goal of this research work is to highlight antigenic regions founded in streptokinase molecule and to give strategy to remove these antigenic sites.

Received | March 07, 2020; Accepted | April 06, 2020; Published | May 15, 2020

*Correspondence | Ghulam Akbar, Department of Biochemistry,University of Agriculture, Faisalabad,38000,Pakistan; Email: ghulamakbardgk@ gmail.com

Citation $\mid$ Akbar, G., M.A. Zia,A.Ahmad, N. Arooj and S. Nusrat. 2020. Review on streptokinase with its antigenic determinants and perspectives to develop its recombinant enzyme with minimum immunogenicity. Journal of Innovative Sciences, 6(1): 17-23.

DOI | http://dx.doi.org/10.17582/journal.jis/2020/6.1.17.23

Keywords | Cardiovascular arrest, Fibrinolytic, Streptococcus, Antigenicity minimization

\section{Introduction}

$\mathrm{C}$ hemical reactions take place in all living cells are catalyzed by enzymes. Enzymes are biological catalysts which can speed up the rate of biochemical reactions happening in the cell (Nelson et al., 2008). Thrombolytic enzymes are formed by many of the living organisms for example snakes, earthworms, Actinomycetes and fungi: Fusarium oxysporum, Mucor sp. bacteria: $S$. equisimilis, $S$. poygens, $S$. mutans, $S$. dysgalactiae, Bacillus natto (Jian Sha et al., 2003).

The Streptococcal species commonly $\beta$-hemolytic Streptococcus produce streptokinase (Ryan et al., 2004). Streptokinase is a protein nature enzyme comprising 414 amino acid residues produced by Streptococcal bacterial species. The most commonly being used thrombolytic agent in Asians and underdeveloped countries is the streptokinase with its boost reactivity and low-cost drug. Despite of this advantage streptokinase has limited use due to the production of antibodies against bacterial origin streptokinase. These generated antibodies effect remains many years after streptokinase administration. However, blood coagulation, which is the primary reason of death, may occur as a consequence of disturbance in homeostasis. Maintenance of internal environment of the cell or body with any change in external environment is called homeostasis (Diwedi et al., 2005).

Blood clump or thrombosis is the development of a thick, jelly like material from liquid blood in the blood vessels of animals. This formation of blood clot can promote to various life frightening disorders like acute myocardial infarction, pulmonary embolism, acute ischemic stroke, deep Venus thrombus and 
arterial embolism. Streptokinase is the best decision for the treatment of these disorders because of minimal effort and effective action to break down blood clump. In any case, it is the major fibrinolytic drug which has been utilized in the undeveloped and underdeveloped countries (Mobarrez et al., 2015).

But there are some side effects of this fibrinolytic drug like intracerebral and gastrointestinal hemorrhage, allergic reactions: chills, fever, itching, nausea, respiratory trouble, skin rashes and anaphylactic reaction. Among these side effects the main problem are the life threatening allergic reactions due to immunogenic streptokinase production from bacterial strains. There are many antigenic sites on streptokinase molecule have been identified which are additionally added by the infectious Streptococci strains into the streptokinase sequence. By removing these immunogenic parts least immunogenic streptokinase has been produced. $\alpha$-domain: (1-146 a.a) stabilizes proper conformation of SK for full activation. Antigenic regions of $\alpha$-domain $3-7,4$ -8, 1-13, 1-20 ,96-99, 138, 120-140, 130-149. $\beta$-domain (147-290 a.a), is the region responsible for high affinity interaction between SK and Plg. Ser60-Lys333 peptide of SK is required for minimal activator activity and antigenic regions of $\beta$-domain are 170-189, 1-253, 238-246. $\gamma$-domain (291-414) has a close contact with Plg active site. Immunogenic sites of $\gamma$-domain are 120-352, 390-399, 353-414, 373-414.

The antigenicity in c-terminal region of streptokinase has been identified. The truncation of 42 amino acid residues on $\mathrm{C}$-terminal region resulted in the reduction of immunogenicity. The antibody count against streptokinase in the serum has been found to be reduced as compared to the normal streptokinase. Another deletion at $\mathrm{C}$-terminal region including 1-59 amino acids from the streptokinase molecule has been found to decrease in plasminogen activator activity and antigenicity as compared to the natural streptokinase.

The ten patients were tested from which eight were immunogenic with the sequence of 130-149, seven patients were immunoreactive to $170-189$ region, in six patient's antigenicity was expressed with the region 1-20 and 380-399, and five patients' sera showed anti-streptokinase antibodies with 390-409 amino acid sequence. The sera of $30 \%$ of the tested patients were immune-reactive by the peptides $50-69,60-79$, 260-279, 270-289, 280- 299, 320-339, and 350-369 and the sera of one patient identified the other seven peptides. There was a difference in the reactivity of different peptides in various patients (Torrens et al., 1999). The truncation of the regions from wild type SK60-386 and SK143-386 separately have been found to decrease in the immunogenicity and to increase in fibrin specificity (Arabi et al., 2011). Streptokinase region 96-99, 4-8 and 120-140 amino acid residues were also recognized as immunogenic epitopes when treated against human and murine antibodies (Coffey et al., 2001: Parhami-Serena et al., 2003).

In circulatory system the blocking of blood vessels due to the formation of solid jelly like blood clots is called thrombosis. Thrombosis is happening as the blood vessel is harmed and the body assembles fibrin molecules and platelets to form blood clump at the damaged site to stop blood loss. The broken part of clump that is wandering in the circulatory system is known as embolus (Furie et al., 2008; Handin et al., 2005).

Arg561 Val562 linkage of the plasminogen is cleaved that synthesizes a bridge of salt by the association with Asp740 due to which change in conformation of plasminogen occurs that transform it to the plasmin (Loy et al., 2011).

\subsection{Antigenicity in streptokinasel Streptokinase Immunogenicity}

Approximately 900,000 American people affected each year by thrombotic diseases resulting to about 100,000 premature deaths. Heart diseases mortality ratio per 100,000 people in some western countries are Slovak republic 674, Hungry 598, Estonia 554, Czech republic 513, Poland 476, Greece 360, Slovenia 345, Germany 314, Austria 313, Maxico 310, Finland 292, Sweden 291, New Zealand 277, Ireland 277, Iceland 272, Italy 261 and America 256. About $80 \%$ cardiovascular patient's death occur due heart attack however greater than $75 \%$ deaths occur in underdeveloped and low-income countries. From all the deaths along the World it is estimated that $31 \%$ people die due to heart diseases per year so these are the highest cause of death along the globe (WHO, 2016). A continuous enhancement in cardiovascular diseases (CVDs) occurring in China and Japan which is totally different in America where CVDs are not increasing. In Europe and America there is decrease in 
CVDs threat factors such as cholesterol, hypertension and diabetes while these factors are arising in Asia and specially in Japan, China, Russia, Pakistan and India (Masafumi et al., 2015).

- There are many regions identified in bacterial origin streptokinase molecule which are immunogenic and induce the production of antibodies to neutralize its effect. Such a study was performed by Reed and coworkers, they recognized the antigenic regions 1-13, 14-127, $1-253,353-414$ and $120-352$ by treating murine antibodies with streptokinase (Reed et al., 1993).

- Molecular weight of $\mathrm{SK}$ is $47 \mathrm{kDa}$, with 414 amino acid residues single strand polypeptide

- There are three domains of streptokinase $\alpha, \beta$ and $\gamma$.

- $\alpha$-domain: (1-146 a.a) maintains appropriate conformation of streptokinase for its full activation.

- Antigenic regions of $\alpha$-domain 3-7,4 -8, 1-13, 1-20 ,96-99, 138, 120-140, 130-149,

- $\alpha$-domain: (1-146 a.a) stabilize proper conformation of SK for full activation.

- Antigenic regions of $\alpha$-domain 3-7,4 -8, 1-13, 1-20,96-99, 138, 120-140, 130-149,

- $\beta$-domain (147-290 a.a): this domain responsible for more interaction interactions between plasminogen and streptokinase.

- Ser60-Lys333 peptide of SK needed for least activator activity

- Antigenic regions of $\beta$-domain 170-189, 1-253, 238-246

- $\quad \gamma$-domain (291-414): This domain has a great interaction to Plasminogen active site.

- Immunogenic sites of $\gamma$-domain are 120-352, 390-399, 353-414, 373-414 (Zhai et al., 2003).

It was identified by the analysis of scanning that streptokinase start to $\mathrm{NH}_{2}$-terminal alpha-domain with minimum interaction for the plg activation (Mukherjee and Vasquez, 2011).

Streptokinase having microbial origin expresses antigenic activity limitizes its clinical application for myocardial arrest and other thrombotic disorders to human being. However, its use may cause intracerebral and gastrointestinal hemorrhage allergic reactions: chills, fever, itching, nausea, respiratory trouble, skin rashes anaphylactic reaction (Kumolosasi et al., 2013). Detrimental responses against antigenic substance are initiated by the defense system producing antibodies is called as hypersensitivity. The famous four types of reactions hypersensitivity have been reported in human beings in which type 1 is mostly involved as the streptokinase hazard effects (Nakamura et al., 2014). Both terminal (carboxyl and amino) sequences of streptokinase protein play important role for streptokinase proper function: $\mathrm{C}$-terminus play a role in complex formation with plasminogen while $\mathrm{N}$-terminus is involved in the activation of plasminogen (Mukherjee and Vasquez, 2011).

\subsection{Evaluation w.r.t. antigenicity and stability}

In 1991, concluded by some scientists that 5 antigenic epitopes were recognized on the molecules of SK. This recognition was done by the $\mathrm{CD}^{4+} \mathrm{CR} \alpha \beta^{+}$ $\mathrm{T}$ cells. These five immunogenic regions are 1-236, 239-346, 348-369, 371-415, Met 237, Met 347, Met 36. Antigenic epitope of 371-415, 348-369, were also identified by $4 \mathrm{~T}$ cells and 3 Tcells respectively (Brusered et al., 1992). It is strongly believed that deletion of these antigenic sites or substitution of identified immunogenic sequences through base excision process their allergic effect was minimized. However, performing all this procedure of truncation in streptokinase molecule preference should be that after synthesizing truncated SK molecule it should be in stable and active form.

$\mathrm{N}$-terminal part of the SK molecule responsible for stable conformation if its part is truncated then molecule loses stability along with disturbed homeostasis. Therefore, researchers are trying their best to find such antigenic regions which have minimum effect on streptokinase stability and functional activity (Nihalani et al., 1998).

\subsection{Truncation of antigenic regions}

Scientists are trying to remove the immunogenicity and other unwanted side effects of streptokinase due to its low cost and efficient activity. The removal of $\mathrm{N}$-terminal 59 amino acid residues improved its fibrin selectivity. The general process to synthesize a recombinant protein is given in the Figure 1.

A large number of experimental trials in cardiovascular arrested patients indicated that infusion of streptokinase is related in decreased long and short-term death rate relative to other untreated patients. Many other features were conferred including origin of streptokinase, its mechanism of action, conformational variability, however detailed investigation was made on production of recombinant 
SK, its clinical applications and its enhanced yield (Kumar et al., 2012). The sequence of skc-2 gene synthesized polypeptide streptokinase consisting antigenic sequences in the $\mathrm{CO}_{2}$-terminal. Truncation of $\mathrm{C}-42$ peptide sequence of streptokinase resulted decreased antigenicity and lower activity (Torrens et al., 1999).

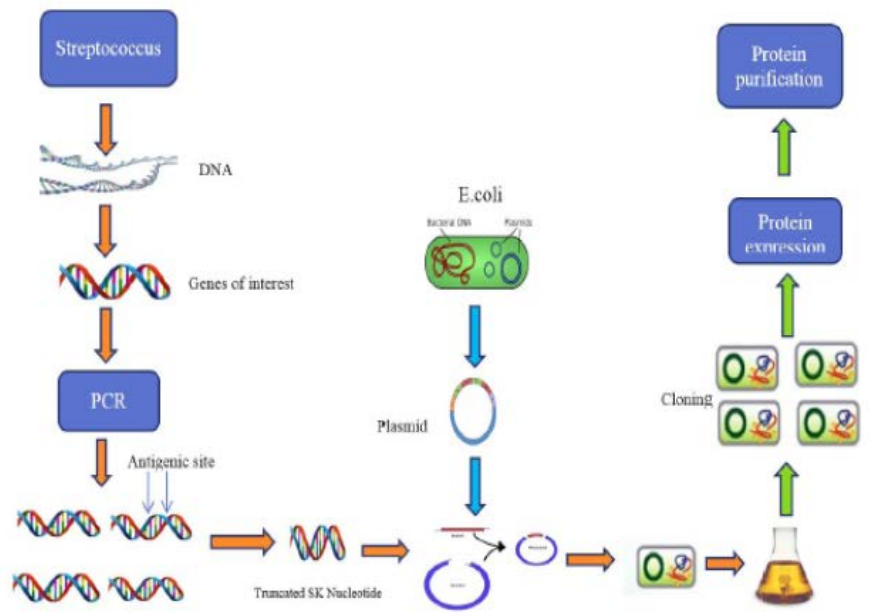

Figure 1: General process of recombinant protein expression.

Eighteen amino acid residues truncation from $\mathrm{NH} 2$-teminal of streptokinase and fifty-one amino acid residues from $\mathrm{CO}_{2}$-terminal considered as effective fibrinolytic molecule (Pimienta et al., 2007). Antigenicity was compared with its activity of 143386 amino acids containing molecule (having 45\% decreased reactivity and $31 \%$ increased activity) with wild type streptokinase molecule (1-414 a.a). Another truncated molecule 60-386 expressed 28\% decreased reactivity and $35 \%$ enhanced functionality relative to complete streptokinase molecule (Arabi et al., 2011). By the removal of 42 amino acids from $\mathrm{CO} 2$-terminal recombinant SK was prepared and its antigenicity was observed by ELIZA plates that were linked by recombinant streptokinase to act against antibodies. In the patients of cardiovascular arrest there were 96 serum tests and 27 patients were treated with streptokinase. The antibodies production was three times greater than in the serum of untreated patients than SK administrated patients (Bandehpour et al., 2012).

\subsection{Cloning and expression of recombinant streptokinase} Cloning is the process in which production of identical copies of a DNA fragments, entire organism or a cell will be obtained. Once after getting many amplified fragments of SK sequences by PCR then truncated
SK will be cloned. It is also the purpose of cloning to analyze the constancy of truncated streptokinase protein. The correct structure of required protein can be identified by treating it to the specific substrate such as in circumstance of SK substrate is plasminogen (Wakeham et al., 2002). The expression of genes of recombinant SK will be carried out by pet expression vector, DNA ligase and TA cloning kit (Mirjamali et al., 2014).

\subsection{Future perspectives}

Streptokinase is widely being used for the treatment of ischemic heart stroke and other myocardial infarctions. However, its immunogenicity in humans and other animals reduces its applications. Therefore, it is necessary to remove its antigenicity at genome level. In future with the use of CRISPR Cas technology will be helpful for removal of antigenic regions from streptokinase genes present in microbial genome. This emerging genome editing technology have revolutionized in many fields based on genome editing aspects.

\section{Conclusions and Recommendations}

There are many immunogenic sites in the streptokinase molecule which trigger immune responses. However, bacterial origin streptokinase when administrated to the patients of cardiovascular diseases it produces antibodies against these antigenic determinants. It is concluded that after deletion of immunogenic sites this low-cost recombinant streptokinase of minimum antigenicity can be used several times for the treatment of cardiovascular patients.

\section{Acknowledgement}

No financial assistance was obtained for this review paper

\section{Author's Contribution}

Conceived and designed the experiments: Ghulam Akbar, Muhammad Anjum Zia, Ali Ahmad, Neha Arooj and Shahneela Nusrat. Analyzed the data: Ghulam Akbar, Muhammad Anjum Zia, Ali Ahmad, Neha Arooj and Shahneela Nusrat. Contributed materials/analysis/tools: Ghulam Akbar, Muhammad Anjum Zia, Ali Ahmad, Neha Arooj and Shahneela Nusrat. Wrote the paper: Ghulam Akbar, Muhammad Anjum Zia, Ali Ahmad, Neha Arooj and Shah- 
neela Nusrat.

Conflict of interest

The authors have declared no conflict of interest.

\section{References}

Arabi, R., Roohvand, F., Norouzian, D., Sardari, S., Aghasadeghi, M.R., Khanahmad, H. and Motevalli, F., 2011. A comparative study on the activity and antigenicity of truncated and fulllength forms of streptokinase. Polish Journal of Microbiology, 60(3): 243-251. https://doi. org/10.33073/pjm-2011-034

Bandehpour, M., Sharifnia Z., Mohajeri N., Taherkhani M., Koochaki A., Yarian F., et al. 2008. comparative study of the reactivity of natural and mutated streptokinase recombinant protein. Iran Journal of clinical Infectious Disease, 3:179-83.

Bruserud, Ø., Elsayed, S. and Pawelec, G., 1992. At least five antigenic epitopes on the streptokinase molecule are recognized by human CD4+ TCR $\alpha \beta+$ T cells. Molecular immunology, 29(9): 1097-1104. https://doi.org/10.1016/01615890(92)90042-V

Coffey, J.A., Jennings, K.R. and Dalton, H., 2001. New antigenic regions of streptokinase are identified by affinity-directed mass spectrometry. European Journal of Biochemistry, 268(19): 5215-5221. https://doi. org/10.1046/j.0014-2956.2001.02472.x

Diwedi, S.K., Hiremath, J.S., Kerkar, P.G., Reddy, K.N., Manjunath, C.N., Ramesh, S.S. and Rao, R.,2005.Indigenous recombinant streptokinase vs natural streptokinase in acute myocardial infarction patients: phase III multicentric randomized double blind trial.

Furie, B. and Furie, B.C., 2008. Mechanisms of thrombus formation. New England Journal of Medicine, 359(9): 938-949. https://doi. org/10.1056/NEJMra0801082

Handin, R.I. 2005. "Chapter 53: bleeding and thrombosis". In Kasper DL, Braunwald E, Fauci AS, et al. Harrison's Principles of Internal Medicine, (16th ed.). New York, NY: McGrawHill. ISBN 0-07-139140-1.

Jamali, L., Ibupoto, K., Chattha, S. and Laghari, R., 2012. Study on physiological weight loss in onion and garlic varieties during storage. Pakistan Journal of Agriculture: Agricultural Engineering Veterinary Sciences, 28: 156-165.
Jian Sha, C.L., Galindo V., Pancholi V.L., Popov Y., Zhao C.W.H., Chopra A.K. 2003. Differential expression of the enolase gene under in vivo versus in vitro growth conditions of Aeromonas hydrophila. Microbial pathogenesis, 34: 195-204.

Kitakaze, M., 2015. Trends in characteristics of CVD in Asia and Japan: the importance of epidemiological studies and beyond. https:// doi.org/10.1016/j.jacc.2015.05.035

Kumar, P.S., Pulicherla, K.K. and Sambasiva, K.R.S., 2012. Current Status of Production, Clinical Usage and Market Scenario of Streptokinase. Journal of Proline, 5: 4223-4229.

Kumolosasi, E., Ws, W. and Ce, W., 2013. The use of thrombolytic agents in acute myocardial infarction (AMI) patients. International Journal of Pharmacy and Pharmaceutical Sciences, 4511: 31-43.

Loy, J.A., Lin, X., Schenone, M., Castellino, F.J., Zhang, X.C. and Tang, J., 2001. Domain interactions between streptokinase and human plasminogen. Biochemistry, 40(48): 1468614695. https://doi.org/10.1021/bi011309d

Maity, J.P., Chakraborty, A., Saha, A., Santra, S.C. and Chanda, S., 2004. Radiation induced effects on some common storage edible seeds in India infested with surface microflora. Radiation in Physics and Chemistry,71(5):1065-1072.https:// doi.org/10.1016/j.radphyschem.2003.10.014

Masafumi, K. 2015. Trends in Characteristics of CVD in Asia and Japan: The Importance of Epidemiological Studies and Beyond.Journal of American College Cardiology, 2: 196-198.

Mirjamali, N.A.S., Soufian, S., Molaee, N., Abbasian, S.S. and Abtahi, H., 2014. Cloning and expression of the enzymatic region of Streptococcal hyaluronidase. Iranian Journal of Basic Medical Sciences, 17(9): 667.

Mobarrez, M., Bandehpour, M., Salehmoghadam, M. and Kazemi, B., 2015. Fibrinolytic activity of recombinant mutant streptokinase. Novelty in Biomedicine, 3(2): 89-93.

Mukherjee, A. and Vasquez, K.M., 2011. Triplex technology in studies of DNA damage, DNA repair, and mutagenesis. Biochimie, 93(8): 1197-1208. https://doi.org/10.1016/j. biochi.2011.04.001

Mundada, L.V., Prorok, M., DeFord, M.E., Figuera, M., Castellino, F.J. and Fay, W.P., 2003. Structure-function analysis of the streptokinase amino terminus (residues 1-59). Journal of 
Biological Chemistry, 278(27): 24421-24427. https://doi.org/10.1074/jbc.M301825200

Nahavandi, A. and Malekzadeh, A.R., 1988. Acculturation in mergers and acquisitions. Academy of Management Review, 13(1): 79-90. https://doi.org/10.5465/ amr.1988.4306790

Nakamura, J., Mutlu, E., Sharma, V., Collins, L., Bodnar, W., Yu, R. and Swenberg, J., 2014. The endogenous exposome. DNA Repair, 19: 3-13. https://doi.org/10.1016/j.dnarep.2014.03.031

Negi, R., Kashyap, R., Prashar, A., Sharma, B., Asotra, S. and Gupta, D., 2017. Pattern of drug-induced bleeding in a tertiary care hospital. International Journal of Research in Medical Sciences, 5(4): 1198. https://doi. org/10.18203/2320-6012.ijrms20170991

Nelson, D.L., Lehninger, A.L. and Cox, M.M., 2008. Lehninger principles of biochemistry. Macmillan.

Nihalani, D., Kumar, R., Rajagopal, K., and Sahni, G., 1998. Role of the amino terminal region of streptokinase in the generation of a fully functional plasminogen activator complex probed with synthetic peptides. Protein Science., 7: 637-648.

Parhami-Seren, B., Seavey, M., Krudysz, J. and Tsantili, P., 2003. Structural correlates of a functional streptokinase antigenic epitope: serine 138 is an essential residue for antibody binding. Journal of Immunological Methods, 272(1-2): 93-105. https://doi. org/10.1016/S0022-1759(02)00435-0

Pimienta, E., Ayala,J.C., Rodríguez, C., Ramos, A., Van Mellaert, L., Vallín, C. and Anné, J., 2007. Recombinant production of Streptococcus equisimilis streptokinase by Streptomyces lividans. Microbial Cell Factories, 6(1): 20. https://doi.org/10.1186/1475-2859-6-20

Reed, G.L., Kussie, P. and Parhami-Seren, B., 1993. A functional analysis of the antigenicity of streptokinase using monoclonal antibody mapping and recombinant streptokinase fragments. The Journal of Immunology, 150(10): 4407-4415.

Ryan, K.J., and C.G. Ray, eds. 2004. Sher. Medical Microbiology, (4th ed.). McGraw Hill. pp. 2934. HYPERLINK "https://en.wikipedia.org/ wiki/International_Standard_Book_Number" Isbn HYPERLINK "https://en.wikipedia.org/ wiki/Special:BookSources/0-8385-8529-9"

\section{0-8385-8529-9}

Sazonova, I.Y., Robinson, B.R., Gladysheva, I.P., Castellino, F.J. and Reed, G.L., 2004. $\alpha$ Domain deletion converts streptokinase into a fibrindependent plasminogen activator through mechanisms akin to staphylokinase and tissue plasminogen activator. Journal of Biological Chemistry, 279(24): 24994-25001. https://doi. org/10.1074/jbc.M400253200

Torrèns, I., Ojalvo, A.G., Seralena, A., Hayes, O. and de la Fuente, J., 2000. A mutant streptokinase lacking the $\mathrm{C}$-terminal 42 amino acids is less immunogenic. Immunology Letters, 70(3): 213-218. https://doi.org/10.1016/S01652478(99)00151-0

Torréns, I., Ojalvo, A.G., Seralena, A., Pupo, E., Lugo, V. and Páez, R., 1999. A mutant streptokinase lacking the $\mathrm{C}$-terminal 42 amino acids is less reactive with preexisting antibodies in patient sera. Biochemical and Biophysical Research Communications, 266(1): 230-236. https://doi.org/10.1006/bbrc.1999.1793

Torréns, I., Reyes, O., Ojalvo, A.G., Seralena, A., Chinea, G., Cruz, L.J. and de la Fuente, J., 1999. Mapping of the antigenic regions of streptokinase in humans after streptokinase therapy. Biochemical and Biophysical Research Communications, 259(1): 162-168. https://doi. org/10.1006/bbrc.1999.0747

Wakeham, N., Terzyan, S., Zhai, P., Loy, J.A., Tang, J. and Zhang, X.C., 2002. Effects of deletion of streptokinase residues 48-59 on plasminogen activation. Protein Engineering, 15(9): 753-761. https://doi.org/10.1093/protein/15.9.753

WHO.,22 September, 2016: "Global Hearts", a new initiative from the World Health Organization (WHO) and partners launched on the margins of the UN General Assembly, aims to beat back the global threat of cardiovascular disease, including heart attacks and strokes - the world's leading cause of death.

World Health Organization., 2017. Programme Budget matters: Programme Budget 2016-2017: Implementation and mid-term review (No. SEA/RC70/4). World Health Organization. Regional Office for South-East Asia.

Yoo, K.S. and Pike, L.M., 2001. Determination of background pyruvic acid concentrations in onions, allium species, and other vegetables. Science Horticulture, 89: 249 - 256. https://doi. org/10.1016/S0304-4238(00)00196-5 
Zhai, P., Wakeham, N., Loy, J.A. and Zhang, X.C., 2003. Functional roles of streptokinase formation and substrate recognition in C-terminal flexible peptide in active site plasminogen activation. Biochemistry, 42(1): 114-120. https://doi.org/10.1021/bi026746m 